\title{
Biochemical Evaluation of Resistance Responses of Potato to Different Isolates of Alternaria solani
}

\author{
Hadis Shahbazi, Heshmatollah Aminian, Navazollah Sahebani, and Dennis A. Halterman
}

First, second, and third authors: Department of Plant Protection, Aboryhan Campus, Tehran University, P.O. Box 33955-159, Tehran, Iran; and fourth author: U.S. Department of Agriculture-Agricultural Research Service, Vegetable Crops Research Unit, Madison, WI 53706. Accepted for publication 18 January 2010.

\section{ABSTRACT}

Shahbazi, H., Aminian, H., Sahebani, N., and Halterman, D. A. 2010. Biochemical evaluation of resistance responses of potato to different isolates of Alternaria solani. Phytopathology 100:454-459.

\begin{abstract}
The resistance phenotypes of nine potato cultivars to five isolates of Alternaria solani, causal agent of early blight, were studied after inoculation and growth under greenhouse conditions. We identified potato cultivars with both susceptible and resistant phenotypes as well as $A$. solani isolates with varying degrees of aggressiveness. Two potato cultivars and two pathogen isolates were selected for biochemical analysis of phenol production and peroxidase activity after inoculation. Phenol compounds were evaluated 2, 4, 6, and 8 days after inoculation, while
\end{abstract}

peroxidase activities were monitored daily for 10 days. Native polyacrylamide electrophoresis was used to identify one protein with peroxidase activity in extracts taken 6 days after inoculation. Significantly higher peroxidase activity as well as total phenol content in potato was correlated with resistance in the Iranian potato cultivar Diamond. Variability of responses within the same cultivar to different isolates of $A$. solani suggests genotypic diversity between isolates that results in phenotypic diversity for pathogen aggressiveness.

Additional keywords: disease resistance, host defense responses, plant peroxidase, plant phenolics.
Early blight, caused by the necrotrophic ascomycetous fungus Alternaria solani (Ellis \& G. Martin) Sorauer, is one of the most common diseases of potatoes, especially where potatoes are grown under irrigation. The disease causes yield losses through defoliation of the plants and severe epidemics of early blight may reduce potato yields by as much as 20 to $30 \%(7,32)$. Early blight can also impact the quality of the harvested tubers. Fungicides used to control the disease are expensive and frequently inefficient (5). The development of potato varieties resistant to early blight remains one of the best strategies for long-term control of this disease.

To date, no monogenic traits conferring resistance to A. solani have been found in potato. Resistance is thought to be correlated with plant age since susceptibility increases as plants grow older $(9,28)$. In tomato, secondary plant metabolites correlated with early blight resistance include phenolic compounds (tannins, flavonols, and phenols) in leaves and stems (1). In addition, the fruit of resistant tomato varieties contain a higher amount of phenolic compounds than those from susceptible varieties (1). The constitutive expression of phenols, which are thought to function as preformed inhibitors, is associated with nonspecific basal resistance to multiple pathogens in all plant species (26). In addition to phenolics, the production of reactive oxygen species, such as hydrogen peroxide and superoxide, also has an integral role in pathogen defense (17). Peroxidase enzymes are important in the production of hydrogen peroxide and have been linked to increased disease resistance in plants (2). Peroxidase also shows affinity to substrates involved in cellular lignification and the

Corresponding author: H. Shahbazi; E-mail address: sah.shahbazi@yahoo.com

doi:10.1094/PHYTO-100-5-0454

This article is in the public domain and not copyrightable. It may be freely reprinted with customary crediting of the source. The American Phytopathological Society, 2010. products of its activity have direct antimicrobial activity in the presence of hydrogen peroxide (29).

In Iran, early blight is a ubiquitous disease that can cause serious crop losses under optimum conditions including high temperature, humidity, and susceptibility and physiological ages of the cultivars. The primary objective of our study was to identify sources of potato early blight resistance and characterize biochemical responses to different isolates of $A$. solani.

\section{MATERIALS AND METHODS}

Cultural conditions. Potato seeds (Solanum tuberosum L.) were planted in plastic pots $(30 \mathrm{~cm}$ diameter) containing soil and perlite under greenhouse conditions $\left(18\right.$ to $\left.25^{\circ} \mathrm{C}\right)$ at Tehran University. Tubers were treated with thiabendazole (tekto WP60\%, Golsam Gorgan Company, Tehran) before planting.

A. solani isolation and spore production. Potato leaves infected with $A$. solani were collected in 2008 from different locations and potato cultivars from Arak Town (Markazi Province) in Iran. Five isolates of $A$. solani were recovered from sections of potato leaves with typical early blight lesions. The leaf sections were surface-sterilized in a $1 \%$ sodium hypochlorite solution for $1 \mathrm{~min}$, rinsed with sterile distilled water, placed on potato dextrose agar (PDA), and incubated under continuous light at $20 \pm 1^{\circ} \mathrm{C}$. Hyphal tips of mycelium that grew from diseased tissue were transferred to petri dishes containing $15 \mathrm{ml}$ PDA. Hyphal-tip sections were incubated for 7 days at $24 \pm 1^{\circ} \mathrm{C}$ on PDA under $16 \mathrm{~h} /$ day near-ultraviolet light (310 to $400 \mathrm{~nm}$ ). Single spores from hyphal-tipped fungal colonies were transferred to PDA dishes to obtain pure cultures of $A$. solani ( $\mathrm{N}$ isolate, AM isolate, $\mathrm{M}$ isolate, $\mathrm{A}$ isolate, and $\mathrm{H}$ isolate). The isolates were maintained on PDA at $20 \pm 1^{\circ} \mathrm{C}$ for 7 days.

Plant inoculations and evaluations. Single spore isolates of $A$. solani were grown on PDA for 6 days at $24 \pm 1{ }^{\circ} \mathrm{C}$ under $16 \mathrm{~h}$ /day near-ultraviolet light ( 310 to $400 \mathrm{~nm}$ ) in order to induce sporulation. Conidia from these in vitro cultures were collected by 
washing with sterile water and diluted to a concentration of $10^{6}$ spores $\mathrm{ml}^{-1}(3,25)$.

Certified seed tubers of $S$. tuberosum 'Diamond', 'Granula', 'Agria', 'Milva', 'Lady rozeta', 'Satina', 'Maradona', 'Sante', and 'Santana' potatoes were planted. Four plants (45 days old) of each cultivar were inoculated separately with each isolate of $A$. solani or a sterile water control. The plants were sprayed with the conidial suspension or sterile water and covered with clear plastic bags for $24 \mathrm{~h}$ to increase humidity and accelerate infection. The plants were grown under normal conditions in the greenhouse at $26^{\circ} \mathrm{C}(3,28)$. The intensity of infection was recorded using the scale described in Table 1 (30). The two cultivars with the lowest and highest early blight infection scores and the two A. solani isolates with the least and greatest aggressiveness were selected for further evaluations.

Phenol assay. Leaf tissue $(0.5 \mathrm{~g})$ was ground in liquid $\mathrm{N}_{2}$ with a mortar and pestle. It was extracted separately in $8 \mathrm{ml}$ of $80 \%$ methanol. The extracts were centrifuged at $4,000 \times g$ for $5 \mathrm{~min}$ (24). To determine the amount of total phenols, $1 \mathrm{ml}$ of leaf extract was placed in test tubes containing $5 \mathrm{ml}$ of distilled water, $250 \mu \mathrm{l}$ of Folin, and $1 \mathrm{ml}$ of $20 \%$ sodium carbonate. The test tubes were stirred and readings were taken after 60 min using an absorbance spectrophotometer at $720 \mathrm{~nm}$. Total phenol was expressed as the milligrams per gram of leaf fresh weight (24).

Peroxidase assays. Leaf tissue was ground in liquid $\mathrm{N}_{2}$ with a mortar and pestle. Approximately $0.5 \mathrm{~g}$ of tissue was transferred to $1 \mathrm{ml}$ of extraction buffer $(0.1 \mathrm{M}$ sodium phosphate, $\mathrm{pH} 6.0)$. Extracts were centrifuged at $14,000 \times g$ for $20 \mathrm{~min}$ at $4^{\circ} \mathrm{C}$ and the supernatant (enzyme extract) was transferred to a new tube on ice until assayed (23). Protein concentration was determined according to Bradford (4) with bovine serum albumin as a standard.

Enzyme extracts (containing $30 \mu \mathrm{g}$ of total protein) were added to $30 \mu \mathrm{l}$ of $200 \mathrm{mM}$ guaiacol and $25 \mathrm{mM}$ citrate phosphate $(\mathrm{pH}$ 5.4). To each sample $30 \mu \mathrm{l}$ of $30 \% \mathrm{H}_{2} \mathrm{O}_{2}$ was added and the absorbance was read at $470 \mathrm{~nm}$ in a UV-VIS spectrophotometer. The activity was calculated as the rate of increase of absorbance per minute, and expressed as unit per milligram of protein (14).

Native PAGE. Isozymes of peroxidase were analyzed by native polyacrylamide gel electrophoresis (PAGE) (31). Samples were prepared by homogenizing $0.5 \mathrm{~g}$ of leaflets from $A$. solani or water-inoculated plants. Alternaria-only samples were prepared from liquid-grown cultures and treated the same as plant tissue samples. Electrophoretic separation was preformed under nondenaturing conditions using a $6 \%$ stacking gel and 12\% separation gel containing Tris-glycine buffer, $\mathrm{pH}$ 8.3. Gels were incubated in $25 \mathrm{mM}$ citrate-phosphate buffer ( $\mathrm{pH}$ 5.4) containing guaiacol for $30 \mathrm{~min}$ and enzyme bands were visualized with a $1 \%$ solution of $\mathrm{H}_{2} \mathrm{O}_{2}$. The gels were photographed and the $\mathrm{R} f$ values of each band were calculated (distance run by isoenzyme/distance run by bromophenol blue).

Analysis of results. All experiments were carried out using a factorial model of a completely randomized experimental design in four replicates per treatment. In greenhouse evaluations, the factorial model was $9 \times 5$, in total phenol determinations it was $2 \times 3 \times 4$ (two potato cultivars $\times$ three treatments: two A. solani isolates and sterile water $\times 4$ days), and in peroxidase assays it was $2 \times 3 \times 10$ (two potato cultivars $\times$ three treatments $\times 10$ days). Statistical analysis was performed using SAS version 9 (20). Analysis of variance was performed on all data sets. A Duncan test with a probability of 0.05 was used to show significant differences between treatments. All data are presented as means. Analyses of variance for greenhouse, peroxidase activity, and total phenol evaluations were significant at the $1 \%$ level $(P<0.01)$.

\section{RESULTS}

Greenhouse evaluations. Greenhouse infection assays of multiple potato cultivars with different isolates of $A$. solani re- vealed significant differences between hosts. The intensity of the infection was determined by visual rating of inoculated plants using a scale from 0 to 100 based on the symptoms described in Table 1. Plants with a lower rating were considered more resistant than those with a high rating. S. tuberosum 'Diamond' exhibited the lowest disease severity with an average score $( \pm$ standard error) of $16( \pm 2)$ among the five A. solani isolates (Fig. 1). Cultivar Granula showed the highest disease severity with an average score of $51( \pm 2)$. Analysis of variance indicated a significant difference between responses of cultivars to A. solani infection. Other cultivars fell between 'Diamond' and 'Granula' with no clear separation between resistant and susceptible cultivars.

Among A. solani isolates used in these assays, isolate A exhibited the highest aggressiveness with an average host disease severity score of $45( \pm 2)$. Isolate $\mathrm{N}$ was the least aggressive with an average host score of $24( \pm 2)$. The other isolates exhibited an intermediate level of aggressiveness $(A>A M>M>H>N)$. No immunity to $A$. solani was observed in any of the cultivars used in this study. Also no significant interactions between a specific isolate and host were observed since the isolates exhibited consistent patterns of aggressiveness. However, since 'Diamond' exhibited significantly less disease severity than 'Granula', we used these two cultivars as well as A. solani isolates A (most aggressive) and $\mathrm{N}$ (least aggressive) to assay defense response differences.

Total phenol. Total phenol content was significantly higher in pathogen-inoculated leaves when compared with healthy, waterinoculated controls (Fig. 2). Total phenol in 'Diamond' was higher than 'Granula' on all days tested. Significant differences in phenolic levels between the two cultivars were observed on all days of the assay (Table 2). In 'Granula', the level of phenolic compounds increased between the second and fourth day, and then decreased up to 8 days after inoculation. Total phenols decreased significantly in 'Diamond' between 2 and 8 days after inoculation.

Differences in total phenol were also observed over time when using isolates of $A$. solani with different aggressiveness phenotypes (Fig. 2). The phenol levels in 'Diamond' and 'Granula' were averaged 2, 4, 6, and 8 days after inoculation with A. solani isolates $\mathrm{A}$ and $\mathrm{N}$. There were significant differences between phenol levels elicited by isolate $\mathrm{A}$, isolate $\mathrm{N}$, and the water control on all days (Table 2). The less aggressive strain $\mathrm{N}$ elicited more total phenol than the more aggressive isolate A. Both A. solani isolates elicited similar patterns of total phenol accumulation compared with the water control with an increase between 2 and 4 days after inoculation followed by a decrease over the next 4 days.

Peroxidase activity. Peroxidase activities were slightly higher in 'Diamond' when compared with 'Granula' and this difference was significant $(P=0.0098$; Table 3$)$. Peroxidase activity in plants inoculated with either $A$. solani isolate $\mathrm{A}$ or $\mathrm{N}$ was higher than in control plants sprayed with water (Fig. 3). When peroxidase activity was monitored over time after inoculation with $A$.

TABLE 1. Scale for evaluation of the foliar damage in potato caused by Alternaria solani

\begin{tabular}{ll}
\hline Rating & Description of symptoms \\
\hline 10 & Spots on lower leaves \\
20 & Spots on most of the lower leaves \\
30 & Spots on all lower and some of the middle leaves \\
40 & Clearly developed blight lesions in lower leaves \\
50 & Blight lesions in lower leaves spread to some middle leaves \\
60 & Blight lesions developed in all inferior and most of the \\
& middle leaves \\
70 & Blight lesions developed in all lower and middle leaves \\
80 & Blight lesions developed in all lower and middle leaves and \\
& spread to upper leaves \\
100 & Total blight (death of the plant)
\end{tabular}


solani isolates in both cultivars Diamond and Granula, the highest activity was observed on the second or third day, depending on the isolate used, while the lowest activity was detected 10 days after inoculation.

Electrophoretic patterns of peroxidase activities on the sixth experimental day are presented in Figure 4. The sixth day was chosen because the peroxidase activity in 'Diamond' was similar in response to the $\mathrm{A}$ and $\mathrm{N}$ isolates, but the isoenzyme banding pattern was most dissimilar. Under native conditions, only one isoenzyme band could be detected in all plant samples and was not present in fungal samples, demonstrating that the peroxidase isoenzyme is derived from plant tissue and not Alternaria. The isoenzyme in 'Diamond' appeared more abundant than in 'Granula' regardless of the A. solani isolate used.

\section{DISCUSSION}

We have shown that resistance to $A$. solani in the resistant potato cultivar Diamond is correlated with increased host defense responses including accumulation of total phenol and elevated peroxidase activity. Resistant and susceptible cultivars Diamond and Granula, respectively, could be significantly separated not only by disease severity scores but also by quantification of total phenol and peroxidase levels.

A. solani isolates with varying degrees of aggressiveness were identified using greenhouse infection assays. Two of these isolates, $\mathrm{A}$ and $\mathrm{N}$, induced significantly more or less disease, respectively, regardless of the host cultivar used. Differences in disease symptomology elicited by isolates $\mathrm{A}$ and $\mathrm{N}$ was also

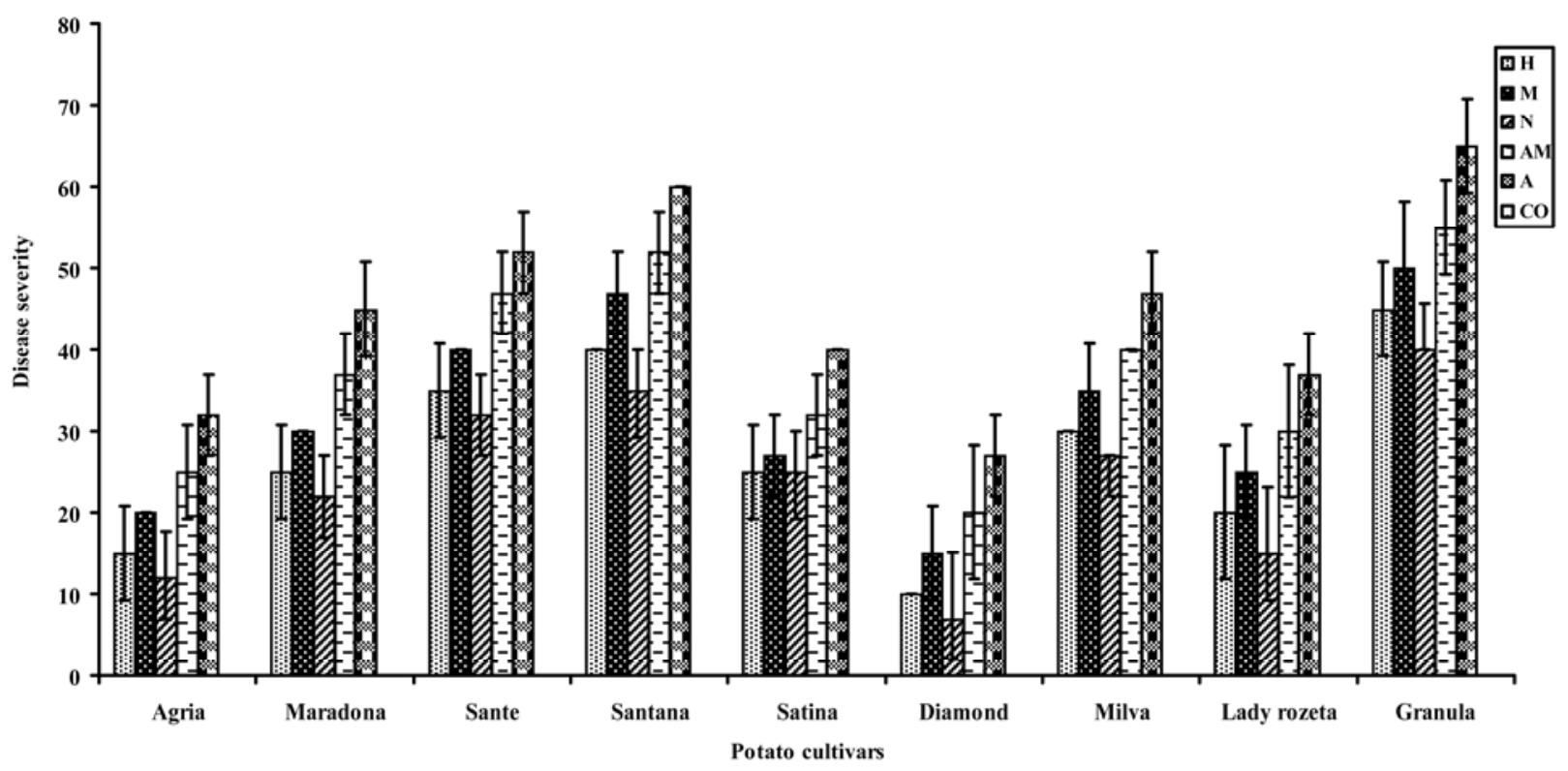

Fig. 1. Disease severity scores of greenhouse-grown potato cultivars inoculated with Alternaria solani isolates (H, M, N, AM, or A) or water (CO). Visual disease symptoms were used to determine disease severity scores according to the scale in Table 1. Bars are presented in the following order: H, M, N, AM, A, and CO. Error bars show the standard error among four replications.

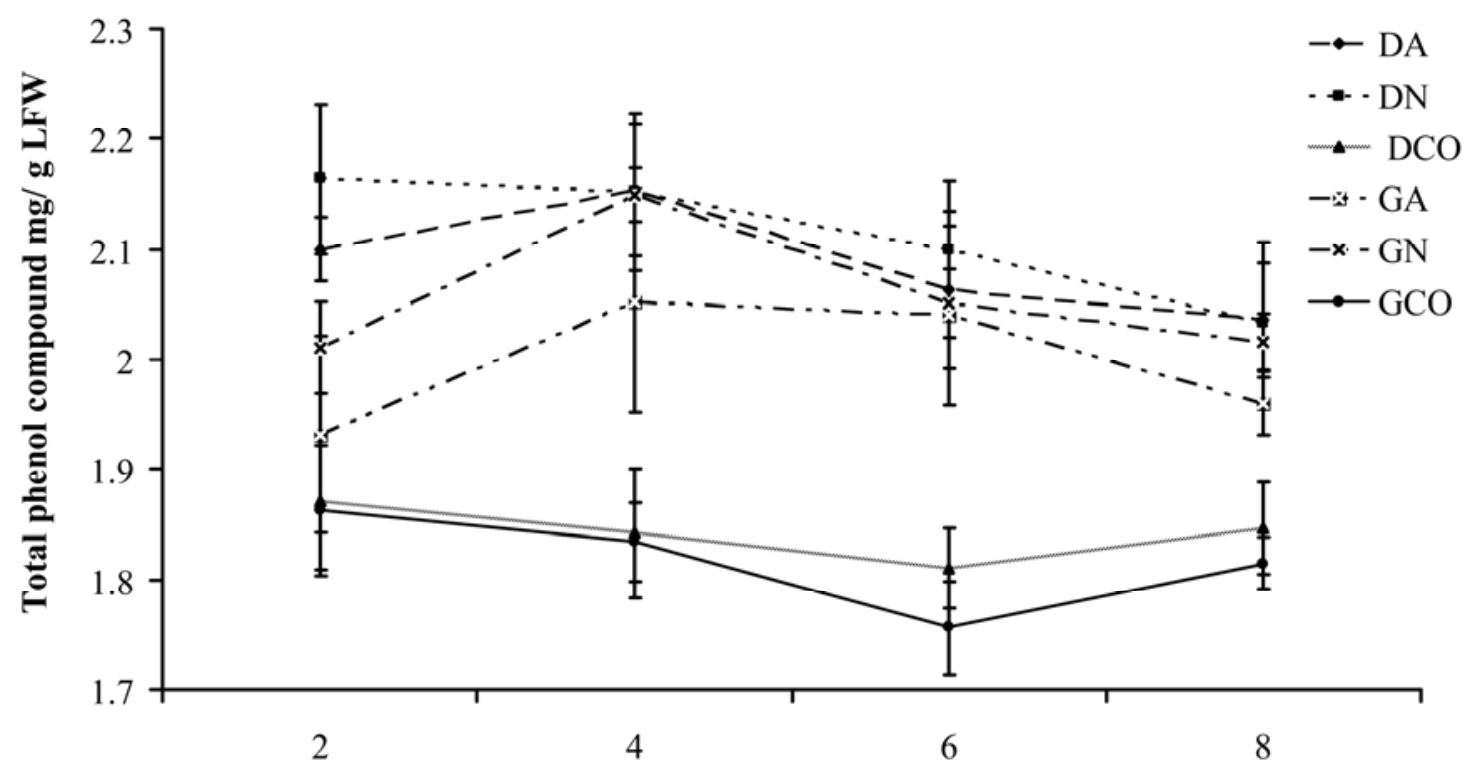

Days after inoculation

Fig. 2. Total phenol levels of potato cultivars Diamond and Granula after inoculation with Alternaria solani. DCO, 'Diamond' sprayed with sterile water; GCO, 'Granula' sprayed with sterile water; GA, 'Granula' sprayed with A. solani isolate A; DA, 'Diamond' sprayed with A. solani isolate A; DN, 'Diamond' sprayed with A. solani isolate N; and GN, 'Granula' sprayed with A. solani isolate N. Results are the means of four replications. Error bars denote standard error. LFW = leaf fresh weight. 
consistent between inoculations for greenhouse evaluations and those for phenol and peroxidase assays. Although genotypic differences have not been established for these isolates, the presence of multiple strains of $A$. solani in potato growing regions is not uncommon $(21,33)$. Isolates from the same host, such as potato, have been found to be more closely related to one another than those collected from another host, such as tomato (34).

TABLE 2. Variance analysis of total phenol in two cultivars after inoculation with two isolates of Alternaria solani ${ }^{\mathrm{a}}$

\begin{tabular}{lccrr}
\hline Source & df & Mean square & $F$ value & $P>F$ \\
\hline Cultivar & 1 & 0.114 & 149.20 & $<0.0001$ \\
Treatment & 2 & 0.022 & 29.85 & $<0.0001$ \\
Day & 3 & 0.010 & 6.98 & 0.0017 \\
Cultivar $\times$ treatment & 2 & 0.005 & 14.10 & $<0.0001$ \\
Cultivar $\times$ day & 3 & 0.016 & 21.14 & $<0.0001$ \\
Treatment $\times$ day & 6 & 0.005 & 7.57 & $<0.0001$ \\
Cultivar $\times$ treatment $\times$ day & 6 & 0.004 & 5.97 & $<0.0001$ \\
Error & 72 & 0.0007 & & \\
\hline
\end{tabular}

${ }^{\text {a }}$ Plants were also treated with water as a control.

TABLE 3. Variance analysis of peroxidase activity in two cultivars after inoculation with two isolates of Alternaria solani ${ }^{\text {a }}$

\begin{tabular}{lrcrr}
\hline Source & df & Mean square & $F$ value & $P>F$ \\
\hline Cultivar & 1 & 0.157 & 5.81 & 0.0098 \\
Treatment & 2 & 0.179 & 6.62 & 0.0004 \\
Day & 9 & 1.020 & 4.14 & 0.0003 \\
Cultivar $\times$ treatment & 2 & 0.112 & 37.37 & $<0.0001$ \\
Cultivar $\times$ day & 9 & 0.097 & 3.59 & $<0.0001$ \\
Treatment $\times$ day & 18 & 0.308 & 11.28 & $<0.0001$ \\
Cultivar $\times$ treatment $\times$ day & 18 & 0.242 & 8.88 & $<0.0001$ \\
Error & 180 & 0.027 & & \\
\hline
\end{tabular}

${ }^{a}$ Plants were also treated with water as a control.
Therefore, among isolates collected from the same host, any genetic variability that translates to differences in aggressiveness is of interest and warrants further study.

Resistance to A. solani in potato is associated with responses that take place after pathogen spore germination, appressoria formation, and penetration (8). Although movement and growth of the pathogen was not assayed in our experiments, the differences between total phenol and peroxidases observed in our experiments took place after the 24 to $36 \mathrm{~h}$ that is typically required for penetration into the leaf tissue (8) suggesting that these responses are a result of intimate contact between host and pathogen. Resistance to $A$. solani in potato is correlated with an HR-like response (defined as autofluorescence, granular cytoplasm, and thickened cell wall but no cell death) (8). However, because of the necrotrophic nature of $A$. solani it is unclear whether a complete HR (including programmed cell death) alone would be capable of inhibiting pathogen spread. It is therefore likely, and consistent with results presented here, that increased defense responses play an important role in responses to $A$. solani. Resistance to several phytopathogens has been attributed to the presence of higher levels of phenol $(13,16,27)$. Additionally, peroxidase is involved in the production of reactive oxygen species, which are directly toxic to the pathogen or indirectly reduce the spread of the pathogen by increasing the cross linking and lignification of the plant cell walls (11). An early increase in peroxidase activity, similar to that in our study, was recorded in the tropical legume Stylosanthes humilis inoculated with Colletotrichum gloeosporioides (12), suggesting that the early induction might have a role in limiting the number of successful infections. In our study however, it is unlikely that production of peroxidase 2 or 3 days after inoculation is associated with the inhibition of penetration of the host since peroxidase activity in both cultivars Diamond and Granula was high but they showed different levels of resistance to both isolates $\mathrm{A}$ and $\mathrm{N}$ on

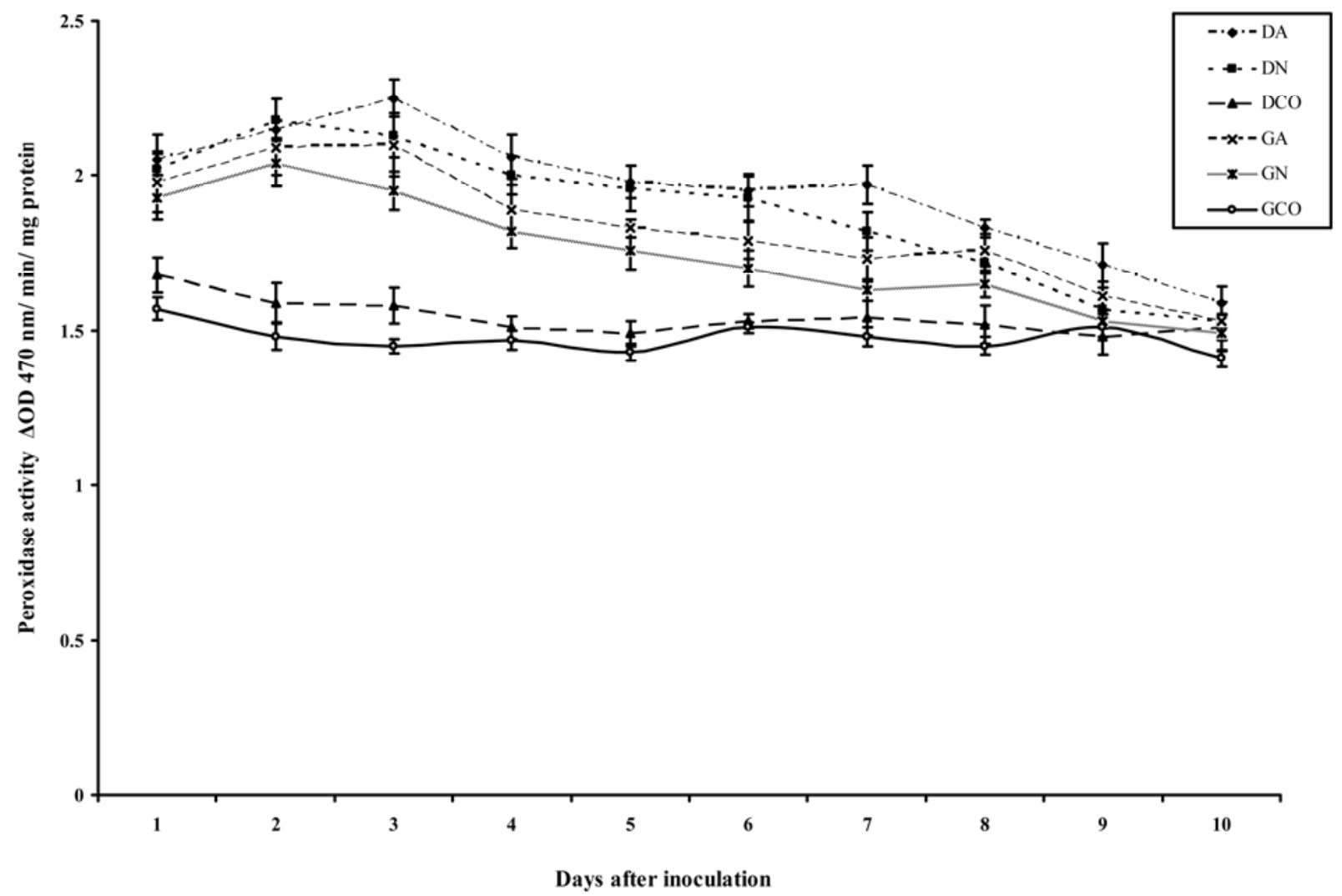

Fig. 3. Peroxidase activity in leaves of potato cultivars Diamond and Granula after inoculation with Alternaria solani. DCO, 'Diamond' sprayed with sterile water; GCO, 'Granula' sprayed with sterile water; GA, 'Granula' sprayed with A. solani isolate A; DA, 'Diamond' sprayed with A. solani isolate A; DN, 'Diamond' sprayed with A. solani isolate N; and GN, 'Granula' sprayed with A. solani isolate N. Results are the means of four replications. Error bars denote standard error. 


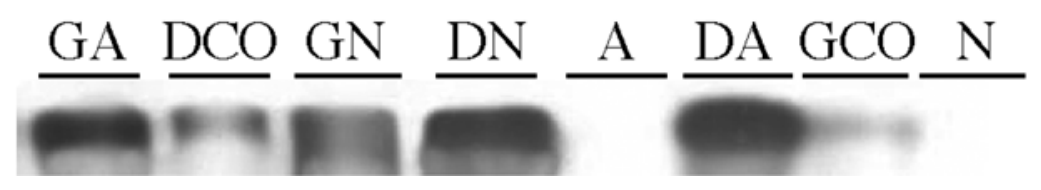

Fig. 4. Isoenzyme patterns of peroxidase identified by native polyacrylamide gel electrophoresis 6 days after inoculation. Samples are shown as follows: DCO, 'Diamond' sprayed with sterile water; GCO, 'Granula' sprayed with sterile water; GA, 'Granula' sprayed with Alternaria solani isolate A; DA, 'Diamond' sprayed with A. solani isolate A; A, A. solani isolate A alone; DN, 'Diamond' sprayed with A. solani isolate N; GN, 'Granula' sprayed with A. solani isolate N; and N, A. solani isolate $\mathrm{N}$ alone.

those days. Together, differences in accumulation of phenolic compounds between resistant 'Diamond' and susceptible 'Granula' as well as changes in peroxidase activity after inoculation indicate that these responses are closely associated with defense responses in cultivated potato only after penetration and intimate contact between the host and pathogen.

The fact that we observed no clear separation between resistant and susceptible potato cultivars suggests that $A$. solani resistance is not monogenic and that varying degrees of resistance are determined by the contribution of multiple defense genes. In addition to environmental variables, factors such as plant age are known to be involved in resistance to early blight $(9,28)$. Plants tested in our greenhouse experiments were of an equally young age (45 days old) and environmental conditions were kept uniform. Therefore, disease severity score differences between cultivars are likely to be due to variation in the host genotypes. Although total phenols and peroxidase activity appear to contribute to resistance to $A$. solani in potato, other factors such as pathogenisis-related $(P R)$ gene expression are likely involved. In tomato, polygenic resistance to $A$. solani is correlated with increased levels of the PR proteins chitinase and $\beta-1,3$-glucanase $(18,19)$. Further analysis of the suite of host responses to early blight is necessary to determine the components critical for adequate resistance to the disease.

Resistance to A. solani has been a focus of potato and tomato breeders for a number of years. However, the development of resistant cultivars has been hampered by both a lack of resistant germplasm sources, the polygenic nature of inheritance, and variability among accessions of the same species $(6,15)$. Difficulty in breeding for resistance is further compounded by the length of time it takes to make phenotypic evaluations of large numbers of individuals in the field. Detached leaf assays do not correlate well with field results $(10,22)$. Greenhouse assays significantly speed the process, however our results suggest that an evaluation of $A$. solani isolates be made before use in greenhouse screening experiments in order to ensure that a highly aggressive isolate has been identified. Alternatively, the correlation between resistance andn defense responses such as phenol production leads to the possibility of using this as a screen for potentially resistant germplasm since we would expect that cultivars with higher basal levels of phenolics are less susceptible than those with lower basal levels.

Understanding the biochemical responses that take place during resistant and susceptible interactions between cultivated potato and $A$. solani will help us to differentiate truly resistant germplasm from cultivars that might contain late-maturity traits that indirectly affect pathogen growth. Not surprisingly, we found considerable variability among resistance traits of cultivated potato varieties. Only nine Iranian potato cultivars were analyzed in our experiments and we would expect to find additional phenotypic diversity among cultivars derived from other breeding programs. Wild potato species also contain diverse sources of $A$. solani resistance traits and biochemical assays that can assist in screening for useful germplasm would be helpful. We also found considerable variation of aggressiveness among different $A$. solani isolates. This variability resulted in quantitative differences in defense responses elicited upon inoculation and suggests that a gene-for-gene interaction, where one major host gene product is responsible for the recognition of a single pathogen gene product, does not exist between the cultivars and isolates used in these experiments.

\section{ACKNOWLEDGMENTS}

We thank Dr. Etebarian (Department of Plant Protection, Aboryhan Campus, Tehran University, Tehran, Iran) for helpful suggestions; and Mr. Lak and Mrs. Mohammadi Far for their valuable support in the study.

\section{LITERATURE CITED}

1. Bhatia, I., Uppal, D., and Bajaj, K. 1972. Study of phenolic contents of resistant and susceptible varieties of tomato (Lycopersicum esculentum) in relation to early blight disease. Indian Phytopathol. 25:231-235.

2. Bindschedler, L. V., Dewdney, J., Blee, K. A., Stone, J. M., Asai, T., Plotnikov, J., Denoux, C., Hayes, T., Gerrish, C., Davies, D. R., Ausubel, F. M., and Bolwell, G. P. 2006. Peroxidase-dependent apoplastic oxidative burst in Arabidopsis required for pathogen resistance. Plant $\mathrm{J}$. 47:851-863.

3. Bokshi, A., Morris, S., and Deverall, B. 2003. Effects of benzothiadiazole and acetylsalicylic acid on $\beta-1,3$-glucanase activity and disease resistance in potato. Plant Pathol. 52:22-27.

4. Bradford, M. M. 1976. A rapid and sensitive method for the quantitation of microgram quantities of protein utilizing the principle of protein dyebinding. Analytical Biochem. 72:248-254.

5. Cassells, A., and Kowalski, B. 1998. Strategies for the evaluation of variation as a source of resistance to early and late blight of potato. Pages 50-60 in: Comprehensive Potato Biotechnology, P. Khurana, R. Chandra and D. Mahesh, eds. Malhotra Publishing House, New Delhi.

6. Chaerani, R., and Voorrips, R. E. 2006. Tomato early blight (Alternaria solani): The pathogen, genetics, and breeding for resistance. J. Gen. Plant Pathol. 72:335-347.

7. Christ, B., and Maczuga, S. 1989. The effect of fungicide schedules and inoculum levels on early blight severity and yield of potato. Plant Dis. 73:695-698.

8. Dita, M. A., Brommonschenkel, S. H., Matsuoka, K., and Mizubuti, E. S. G. 2007. Histopathological study of the Alternaria solani infection process in potato cultivars with different levels of early blight resistance. J. Phytopathol. 155:462-469.

9. Douglas, D., and Pavek, J. 1972. Screening potatoes for field resistance to early blight. Am. Potato J. 49:1-6.

10. Foolad, M. R., Ntahimpera, N., Christ, B. J., and Lin, G. Y. 2000. Comparison of field, greenhouse, and detached-leaflet evaluations of tomato germplasm for early blight resistance. Plant Dis. 84:967-972.

11. Hammond-Kosack, K. E., and Jones, J. D. 1996. Resistance genedependent plant defense responses. Plant Cell 8:1773-1791.

12. Harrison, S., Curtis, M., McIntyre, C., Maclean, D., and Manners, J. 1995. Differential expression of peroxidase isogenes during the early stages of infection of the tropical forage legume Stylosanthes humilis by Colletotrichum gloeosporioides. Mol. Plant-Microbe Interact. 8:398-406.

13. Jain, A., and Yadav, H. 2003. Biochemical constituents of finger millet genotype associated with resistance to blast caused by Pyricularis grisea. Ann. Plant Prot. Sci. 11:70-74.

14. Janda, T., Szalai, G., Rios-Gonzales, K., Veisa, O., and Paldi, E. 2003. Comparative study of frost tolerance and antioxidant activity in cereals. Plant Sci. 164:301-306.

15. Jansky, S. H., Simon, R., and Spooner, D. M. 2008. A test of taxonomic predictivity: Resistance to early blight in wild relatives of cultivated potato. Phytopathology 98:680-687.

16. Kushwaha, K., and Narain, U. 2005. Biochemical changes to pigeon pea leaves infected with Alternaria tenuissinia. Ann. Plant Prot. Sci. 13:415417.

17. Lamb, C., and Dixon, R. A. 1997. The oxidative burst in plant disease resistance. Annu. Rev. Plant Physiol. Plant Mol. Biol. 48:251-275.

18. Lawrence, C. B., Joosten, M. H. A. J., and Tuzun, S. 1996. Differential induction of pathogenesis-related proteins in tomato by Alternaria solani 
and the association of a basic chitinase isozyme with resistance. Physiol. Mol. Plant Pathol. 48:361-377.

19. Lawrence, C. B., Singh, N. P., Qiu, J., Gardner, R. G., and Tuzun, S. 2000. Constitutive hydrolytic enzymes are associated with polygenic resistance of tomato to Alternaria solani and may function as an elicitor release mechanism. Physiol. Mol. Plant Pathol. 57:211-220.

20. Littell, R. C., Milliken, G. A., Stroup, W. W., and Wolfinger, R. D. 1996. SAS System for Mixed Models. SAS Institute, Cary, NC.

21. Lourenço, V., Moya, A., González-Candelas, F., Carbone, I., Maffia, L. A., and Mizubuti, E. S. G. 2009. Molecular diversity and evolutionary processes of Alternaria solani in Brazil inferred using genealogical and coalescent approaches. Phytopathology 99:765-774.

22. Lynch, D., Wastie, R., Stewart, H., Mackay, G., Lyon, G., and Nachmias, A. 1991. Screening for resistance to early blight (Alternaria solani) in potato (Solanum tuberosum L.) using toxic metabolites produced by the fungus. Potato Res. 34:297-304.

23. Madhaiyan, M., Poonguzhali, S., Senthikumar, M., Seshadri, S., Chung, H., Yong, J., Sundram, S., and Sa, T. 2004. Growth promotion and induction of systemic resistance in rice cultivar Co-47 (Oryzea sativa) by Methylobacterium spp. Bot. Bull. Acad. Sin. 45:315-324.

24. Malick, C., and Singh, M. 1980. Plant Enzymology and Histo-Enzymology. Kalyani Publisher, New Delhi.

25. Nadia, G., El-Gamal, G., Abd-El-Kareem, F., Fotouh, Y., and El-Mougy, N. 2007. Induction of systemic resistance in potato plants against late and early blight diseases using chemical inducers under greenhouse and field conditions. Res. J. Agric. Biol. Sci. 3:73-81.
26. Nicholson, R., and Hammerschmidt, R. 1992. Phenolic compounds and their role in disease resistance. Annu. Rev. Phytopathol. 30:369-389.

27. Parashar, A., and Lodha, P. 2007. Phenolics estimation in foeniculum vulgare infected with Ramularia blight. Ann. Plant Prot. Sci. 15:396-398.

28. Pelletier, J., and Fry, W. 1989. Characterization of resistance to early blight in three potato cultivars: Incubation period, lesion expansion rate, and spore production. Phytopathology 79:511-517.

29. Ride, J. 1975. Liginification in wounded wheat leaves in response to fungi and its possible role in resistance. Physiol. Plant Pathol. 5:125-134.

30. Rodríguez, N., Kowalski, B., Rodríguez, L., Caraballoso, I., Suárez, M., Pérez, P., Quintana, C., Gonzalez, N., and Ramos, R. 2007. In vitro and ex vitro selection of potato plantlets for resistance to early blight. J. Phytopathol. 155:582-586.

31. Seevers, D., Daly, J., and Catedral, F. 1971. The role of peroxidase isozyme in resistance to wheat stem rust disease. Plant Physiol. 48:353360.

32. Shtienberg, D., Bergeron, S., Nicholson, A., Fry, W., and Ewing, E. 1990. Development and evaluation of a general model for yield loss assessment in potatoes. Phytopathology 80:466-472.

33. van der Waals, J. E., Korsten, L., and Slippers, B. 2004. Genetic diversity among Alternaria solani isolates from potatoes in South Africa. Plant Dis. 88:959-964.

34. Weir, T. L., Huff, D. R., Christ, B. J., and Romaine, C. P. 1998. RAPDPCR analysis of genetic variation among isolates of Alternaria solani and Alternaria alternata from potato and tomato. Mycologia 90:813-821. 